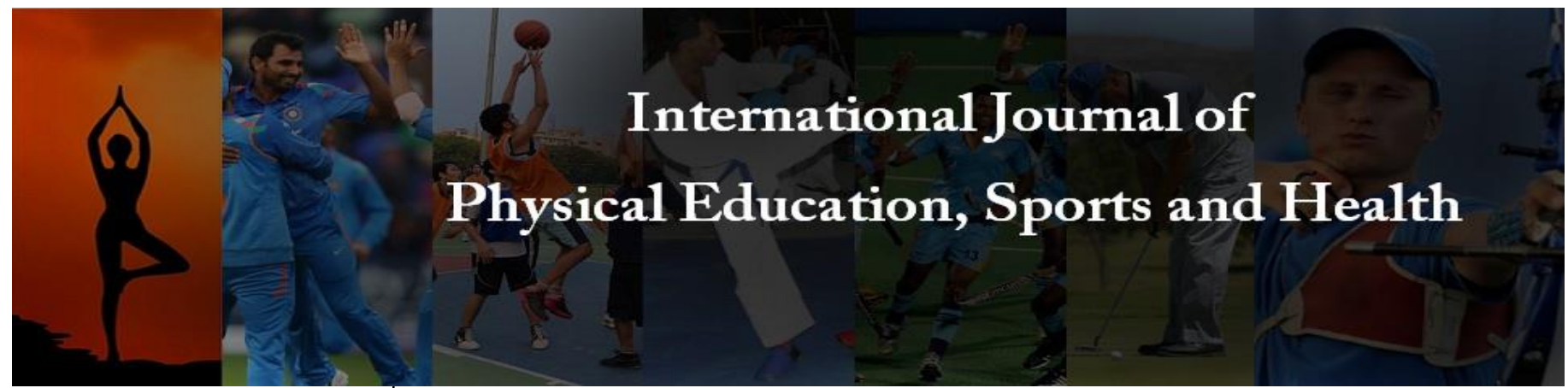

P-ISSN: 2394-1685

E-ISSN: 2394-1693

Impact Factor (ISRA): 5.38

IJPESH 2021; 8(2): 85-88

(C) 2021 IJPESH

www.kheljournal.com

Received: 09-01-2021

Accepted: 14-02-2021

\section{Dilpreet Kaur}

Assistant Professor, Chandigarh University, Chandigarh, India
Corresponding Author:

Dilpreet Kaur

Assistant Professor, Chandigarh

University, Chandigarh, India

\section{Comparative study of Hematocrit among sportsmen of various games}

\section{Dilpreet Kaur}

DOI: https://doi.org/10.22271/kheljournal.2021.v8.i2b.2030

\section{Abstract}

The study was conducted to find out the mean concentration of Hematocrit in sportsmen participating in yoga, Handball, volleyball. Thirty-three sports personals were taken as sample who are aged between 18 to 25 and represented Kurukshetra university in all India inter-university. To find out the difference in the mean concentration statistical techniques were employed. The result of the study shows that there exist significant difference in the mean concentration of Hematocrit within and between all the three categories of sportsmen.

Keywords: Hematocrit, Handball, volleyball, yoga players

\section{Introduction}

Physical activity is an inherent trait of a human being. It becomes all the way imperative to identify the nature and the degree of this natural talent and to nurture, modifies and refines it to get the cherished outcomes. The children perform a lot of activities such as running, jumping, throwing, catching, kicking and striking etc. Today education must not only include the body and knowledge, but also to develop inquiring minds that will enable them to comprehend and accept what is to come tomorrow. To achieve the same adoption of new techniques and methodology is highly required in sports sciences and physical education. The developing tendencies in international sports, especially in team games are identified as the increase in game tempo, tougher body game and greater variability in technique and tactics. An increased performance level can only be achieved by working and training of all major components i.e. technique, coordination, tactics, physical fitness, physiological and psychological qualities. Blood is a lifesaving liquid organ. Whole blood is a mixture of cellular elements, colloids and crystalloids. As different blood components have different relative density, sediment rate and size they can be separated when centrifugal force is applied Hardwick J (2008).

Hematology is the branch of medicine concerned with the study of the cause, prognosis, treatment, and prevention of diseases related to blood National Cancer Institute Dictionary (2014). Several parameters that will be analyzed in this study are.

\section{Hematocrit}

Hematocrit is a blood test, which indicates what percentage of your whole blood volume is specifically made up of erythrocytes, or red blood cells. National Cancer Institute Dictionary (2014).

Normal Range for

Male $-40.7 \%-50.3 \%$

Female - 36.1\%-44.3\% Shrilekha Sairam et al. (2013).

Anđelković M et al. (2015) investigated hematological and biochemical behavior of top football players, in order to get more understanding in the physiological features of these sportsmen and to deliver trainers and sports doctors with useful indicators. 19 male football players offered to participate in this study. We tailed the young top football players during a competitive half season. Venous blood samples were taken between 9:00 and 10:00 a.m. after an overnight fast $(10 \mathrm{~h})$, after 45 and 90 days and hematological and biochemical parameters were checked and found that Hemoglobin and hematocrit levels were considerably condensed over the observational time $(p<0.05)$, but RBC count and iron levels 
remained same. Top football players are characterized by important changes in biochemical and hematological factors over the half season, which are linked to training workload, as well as adaptation made by the soccer training. Their results showed that regular monitoring of the biochemical and hematological factors is fundamental for the identification of a fit status and related best performances by sport doctors and trainers and choice of a correct workload by trainers.

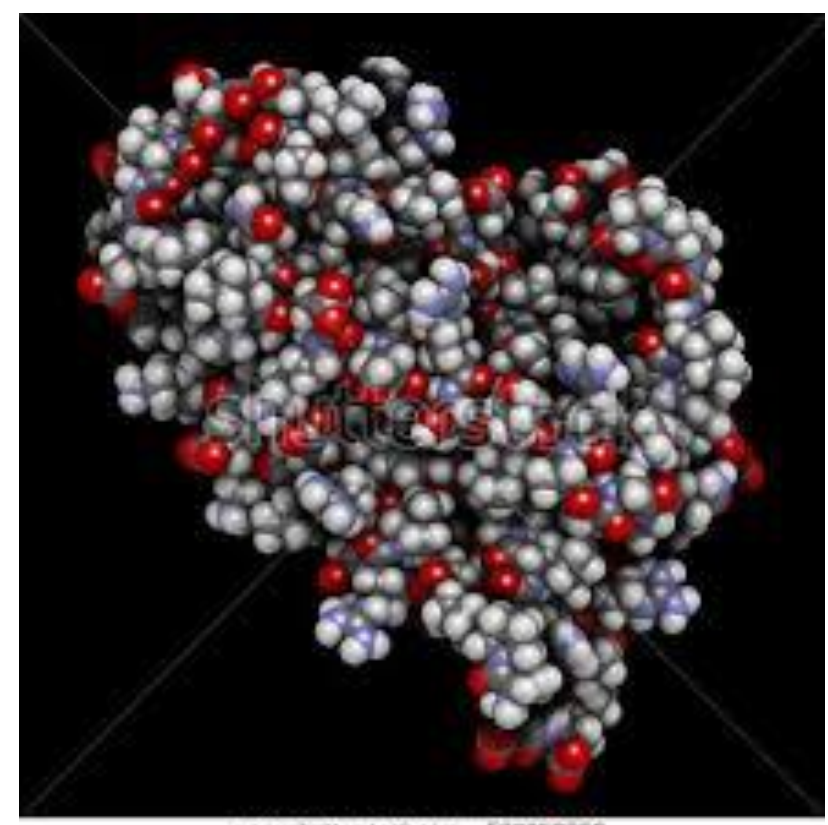

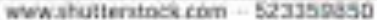

\section{Methodology And Procedure \\ Samples}

In the present study, the purposive sampling sample method was used and60 players were selected. To meet out the objectives of the study only those players were selected as samples, who had represented Kurukshetra University in All India Inter University Tournaments in their respective games. The age of sample ranges between 18 to 25 years. The categorization of subjects is as under:

\section{Categorization of Subjects}

\begin{tabular}{|c|c|c|}
\hline \multicolumn{3}{|c|}{ Men } \\
\hline Yoga & Handball & Volleyball \\
\hline 8 & 10 & 15 \\
\hline \multicolumn{2}{|c|}{ Total $=33$} \\
\hline
\end{tabular}

\section{Normal range}

Male - $40.7 \%-50.3 \%$

Female - 36.1\%-44.3\% Shrilekha Sairam et al. (2013).

\section{Tools Used}

In this study, Hematological Analyzer was used as a tool to measure the mean concentration of various variables of subjects.

\section{Hematological Analyzer Technology}

Hematology analyzers are used widely in patient and research settings to count and characterize blood cells for disease detection and monitoring. Basic analyzers return a complete blood count $(\mathrm{CBC})$ with a three-part differential white blood cell (WBC) count. Sophisticated analyzers measure cell morphology and can detect small cell populations to diagnose rare blood conditions.
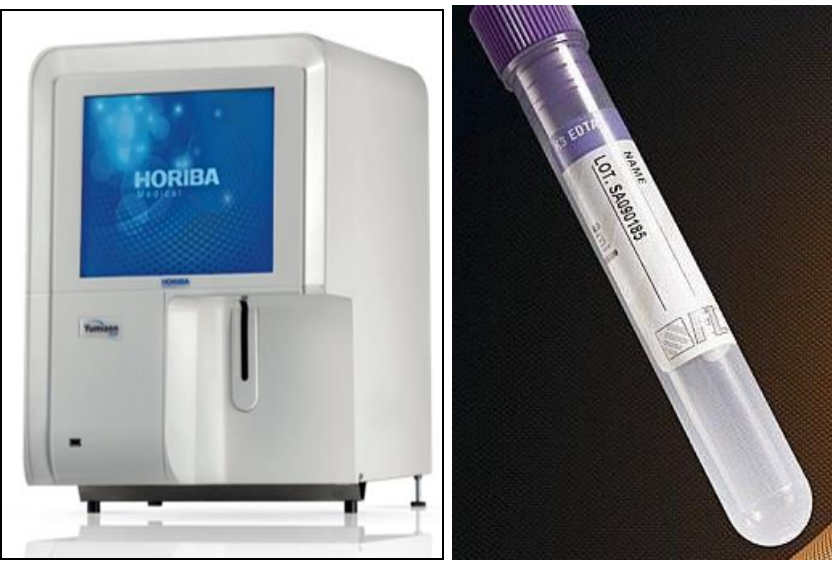

Above concepts.

The Horiba's Yumizen H500 is designed to give the concentration value of 27 parameters including full WBC. It uses the concept of Flow Cytometry and Cytochemistry. The DHSS (Double Hydrodynamic Sequential System) is used for above concepts.

\section{Incubator}

The incubators bundled with this analyzer are used to store blood samples of patients for monitoring. A special serum is to be mixed with blood which is present in these incubators that is essential to keep the blood analyzable for the duration of one hour.

\section{Collection of Data}

The data collected from all the subjects took place during All India Inter University Training Camps for all the games .Proper permissions were taken from respective coaches regarding the sample collection. The blood samples were collected by a trained medical technician from Median Cubital Vein through venipuncture. The venipuncture site was sterilized first with antiseptic soaked cotton and tourniquet was applied near biceps branchi area of upper arm. A fresh IV syringe was used for each of the subject and waste syringes were disposed with utmost care afterwards.

\section{Statistic Techniques Used}

The statistical tools are used to convert the quantitative data into qualitative responses, so that it may be easy to make the calculation and this process is known as quantification of data. The selection of statistical tools depends upon the nature of the data and number of variables included in the investigation. In order to analysis the data in the present study the following statistical techniques were used manually as well as on statistical software program SPSS 16 (Statistical Package for the Social Sciences):

a) Mean: Arithmetic mean was calculated by adding up all the Observations and dividing the sum by the number of individuals.

$$
(\bar{X})=\frac{2 \pi}{N}
$$

Where $\mathrm{N}=$ Total Number of subjects $\sum \mathrm{X}=$ Sum of all individual values.

b) Standard Deviation: It measures the absolute dispersion of variability. It is calculated by following method. 
S.D. $=\sqrt{\frac{\sum X^{2}-\frac{E X 0^{2}}{n}}{n-1}}$

Where $\sum \mathrm{x}^{2}=$ Sum of squares of the individual values. $\left(\sum x\right)^{2}=$ The square of the sum of the individual values.

c) Standard Error of Difference (S.E.D.)

S.E.D. $=\sqrt{\frac{\left(S D_{1}\right)^{2}}{N_{1}}+\frac{\left(S D_{2}\right)^{2}}{N_{2}}}$

Where S.D.1 = Standard Deviation of First Group.

S.D.2 = Standard Deviation of Second Group.

N1 = Number of Sources in First Group.

N2 = Number of Sources in Second Group.

d) t-Test: This test was applied to determine whether the observation differences between two sample means $\mathrm{X} 1$ and $\mathrm{X} 2$ were indicative of real difference or it is due to the sampling error. The t-ratio was calculated with the following formula of t-test:

$$
\begin{array}{ll}
\mathrm{t} & =\left[\frac{\boldsymbol{M}_{1}-\boldsymbol{M}_{2}}{S E D}\right] \\
\text { Where M1 } & =\text { Mean of First Group. } \\
\text { M2 } & =\text { Mean of Second Group. }
\end{array}
$$

e) Anova: The purpose of analysis of variance is to test differences in means (for groups or variables) for statistical significance. This is accomplished by analyzing the variance, that is, by partitioning the total variance into the component that is due to true random error (i.e., within-group SS) and the components that are due to differences between means.

Analysis of Data and Findings

Descriptive Statistics of Hematological Analyzer of subjects for the various categories.

\begin{tabular}{|c|c|c|c|}
\hline Variables & Yoga Male & $\begin{array}{c}\text { Hnadball } \\
\text { Male }\end{array}$ & Volleyball Male \\
\hline $\mathbf{N}$ & $\mathbf{8}$ & $\mathbf{1 0}$ & $\mathbf{1 5}$ \\
\hline HCT & $36.31 \pm 7.07$ & $42.53 \pm 1.41$ & $44.05 \pm 2.69$ \\
\hline
\end{tabular}

\begin{tabular}{|c|c|c|c|c|}
\hline $\begin{array}{l}\text { Source of } \\
\text { Variation }\end{array}$ & $\begin{array}{c}\text { Sum of } \\
\text { Squares }\end{array}$ & df & $\begin{array}{c}\text { Mean Square } \\
\text { Variance }\end{array}$ & $\begin{array}{c}\text { F- } \\
\text { Value }\end{array}$ \\
\hline $\begin{array}{l}\text { Between } \\
\text { Groups }\end{array}$ & 321.69 & 2 & 160.84 & \multirow[t]{2}{*}{$5.61 * *$} \\
\hline Within Group & 859.47 & 30 & 28.65 & \\
\hline Total & 1181.55 & 32 & & \\
\hline
\end{tabular}

Table 1: Analysis of Variance (ANOVA) for Hematocrit of Sportsmen of various categories

\section{Description and Interpretation of table 1.1}

In table 1.1, the Analysis of Variance for the Hematocrit concentration in the Subjects of various categories has been presented. The calculated F-value is 5.61, which is more than the table value $(\mathrm{df}=2 ; 30-5.39)$ at 0.01 levels of significance. It indicates that there exists a significant difference within and between all the three categories of sportsmen for mean concentration of Hematocrit present in their blood. To find out the degree and direction of difference between various categories for Hematocrit concentration further analysis was done with the help of t-test.

Table 2: Significance of difference in mean concentration of Hematocrit present in the Sportsmen of various sports

\begin{tabular}{|c|c|c|c|c|c|c|c|c|}
\hline S. No. & Categories & M1 & M2 & M.D & S.D.1 & S.D.2 & S.E.D. & T value \\
\hline 1. & Yoga v/s Handball & 36.31 & 42.53 & 6.22 & 7.07 & 1.41 & 2.54 & 1.78 \\
\hline 2. & Yoga v/s Volleyball & 36.31 & 44.05 & 7.72 & 7.07 & 2.69 & 2.59 & $\mathbf{2 . 1 9} *$ \\
\hline 3. & Handball v/s Volleyball & 42.53 & 44.05 & 1.51 & 1.41 & 2.69 & 0.83 & 1.33 \\
\hline
\end{tabular}

\section{Description and Interpretation of table 1.2}

Table no. 1.2 represents the significant difference in the mean concentration of Hematocrit present in the blood of sportsmen of various categories. It is indicated in table 1.2 (1) that mean concentration of Hematocrit present in the blood of sportsmen of Yoga and Handball were 36.31 and 42.53 respectively, while Standard Deviation of both the groups was 7.07 and 1.41 respectively. The Standard Error of Difference (SED) of both groups was 2.54 . The calculated t-value is 1.78 , which is less than the table value $(\mathrm{df}=16-1.96)$ at 0.05 level of significance. It indicates that there exists no significant difference in mean concentration of Hematocrit present in the blood of sportsmen of Yoga and Handball.

Table no. 1.2 (2) indicates that mean concentration of Hematocrit present in the blood of sportsmen of Yoga and Volleyball were 36.31 and 44.05 respectively, while Standard Deviation of both the groups were 7.07 and 2.69. The Standard Error of Difference (SED) of both groups was 2.59. The calculated t-value is 2.19 , which is more than the table value $(\mathrm{df}=21-1.96)$ at 0.05 level of significance but less than the table value $(\mathrm{df}=21-2.58)$ at 0.01 level of significance. It indicates that there exists a significant difference in the mean concentration of Hematocrit present in the blood of sportsmen of Yoga and Volleyball. Further as the mean difference is in favor of Volleyball sportsmen, it is concluded that the Volleyball sportsmen were having significantly higher mean concentration of Hematocrit present in the blood in comparison to Yoga sportsmen.

In table no. 1.2 (3), the mean concentration of Hematocrit present in the blood of sportsmen of Handball and Volleyball has been presented which is 42.53 and 44.05 respectively, while Standard Deviation of both the groups were 1.41 and 2.69. The Standard Error of Difference (SED) of both groups was 0.83 . The calculated t-value is 1.33 , which is less than the table value $(\mathrm{df}=23-1.96)$ at 0.05 level of significance. It indicates that there exists no significant difference in mean concentration of Hematocrit present in the blood of sportsmen of Handball and Volleyball

\section{Discussion of Hypotheses}

According to table no. 1.1 the calculated F-value is 5.61, which is more than the table value $(\mathrm{df}=2 ; 30-5.39)$ at 0.01 levels of significance. It indicates that there exists a significant difference within and between all the three categories of sportsmen for mean concentration of Hematocrit present in their blood. Table no.1.2 indicates that there exists no significant difference in mean concentration of Hematocrit present in the blood of sportsmen of Yoga and Handball, that the Volleyball sportsmen were having significantly higher mean concentration of Hematocrit present in the blood in comparison to Yoga sportsmen and there exists no significant difference in mean concentration of Hematocrit present in the 
blood of sportsmen of Handball and Volleyball.

\section{References}

1. Kuipers H, Moran J, Mitchell DW, Shobe J, DubravcicSimunjak S, Sakai Het al. Hemoglobin levels and athletic performance in elite speed skaters during the olympic season 2006. Clin J Sport Med. 2007;17(2):1359.

2. McGowan CJ, Pyne DB, Thompson KG, Raglin JS, Osborne M, Rattray B. Elite sprint swimming performance is enhanced by completion of additional warm-up activities. J Sports Sci 2017;35(15):1493-1499.

3. McLean BD, Buttifant D, Gore CJ, White K, Kemp J. Year-to-year variability in haemoglobin mass response to two altitude training camps. Br J Sports Med 2013, 47.

4. McLean BD, Buttifant D, Gore CJ, White K, Liess C, Kemp J. Physiological and performance responses to a preseason altitude-training camp in elite team-sport athletes. Int J Sports Physiol Perform 2013;8(4):391-9.

5. Nagao N, Imai Y, Arie J, Sawada Y. The Kaike triathletes' hematocrit values. With relation to their competition results. J Sports Med Phys Fitness 1992;32(2):201-5. 